\title{
Tear osmolarity and OSDI symptoms: is there a relationship?
}

\author{
WDH Gillan*
}

The Anterior Eye Research Group, Department of Optometry, University of Johannesburg, PO Box 524, Auckland Park, 2006 South Africa

$<$ wgillan@uj.ac.za>

Received 21 January 2013; revised version accepted 18 June 2013

\section{Introduction}

Dry eye is defined as: "a multifactorial disease of the tears and ocular surface that results in symptoms of discomfort, visual disturbance and tear film instability with potential damage to the ocular surface. It is accompanied by increased osmolarity of the tear film and inflammation of the ocular surface"1.

Dry eye is a ubiquitous disease with estimates of between $5 \%$ and $35 \%$ prevalence being reported in various research studies ${ }^{2-6}$. The diagnosis of dry eye is difficult, in part due to a paucity of information relating to a standardized set of diagnostic criteria and the absence of a "gold standard" as well as the poor correlation between the symptoms that patients present with and the clinical signs that might be observed $^{8,9}$. Various studies have shown that only approximately $57 \%$ of patients presenting with symptoms of dry eye have objective signs of the disease $^{9-11}$. The use of symptomatology (determined using validated symptom questionnaires) in the diagnosis of dry eye disease presents an important and accessible diagnostic tool to clinicians and researchers of dry eye ${ }^{7}$. The diagnostic subcommittee of the International Dry Eye Workshop have stated: "...the administration of a structured questionnaire to patients presenting to a clinic provides an excellent opportunity for screening patients with potential dry eye disease"7. Questionnaires are commonly used to investigate the prevalence of dry eye in various sample groups, in screening for dry eye, to investigate the effects of different dry eye treatment strategies and to grade the severity of dry eye disease states ${ }^{12-19}$. It has also been suggested that questionnaires might be more valuable in diagnosing dry eye than dry eye tests $^{13}$. The outcomes research group at Allergan Incorporated (Irvine, California) developed a 12item questionnaire, the Ocular Surface Disease Index (OSDI), to..."provide a rapid assessment of the symptoms of ocular irritation consistent with dry eye disease and their impact on vision-related functioning" 20 . The validity and reliability of the OSDI were evaluated by Schiffman et $a l^{21}$ who found the OSDI to be a reliable and valid instrument for determining the severity of dry eye disease. Ozcura et $a l^{22}$ also found the OSDI to be a standardized test for the evaluation of symptoms of dry eye and that the instrument can be used to support the diagnosis of dry eye disease. Dougherty et $a l^{23}$, however, show that the OSDI "is not ideally targeted for patients with dry eye disease".

Osmolarity is a measure of the concentration of a solute and is defined ${ }^{24}$ as the number of osmoles of solute per litre of solution $(\mathrm{Osm} / \mathrm{l})$. The process of osmometry is the measuring of solute concentration and takes into account the dissociation of solutes in solution $^{25}$. A convenient, clinical measurement of tear osmolarity has only recently become a reality with the availability of the TearLab ${ }^{\mathrm{TM}}$ osmolarity system. The $\mathrm{TearLab}^{\mathrm{TM}}$ system ..."'is a tear fluid collection and testing device for the quantitative measurement of osmolarity of human tears..." that provides... "a quick 
and simple method of determining tear osmolarity using nanolitre volumes of tear fluid collected from the eyelid margin" 26 . The conclusions of several research articles have stated that tear osmolarity is the best single metric to use in the diagnosis and classification of dry eye ${ }^{8,27-28}$. Sullivan et $a l^{29}$ have stated that tear osmolarity is the best single marker of dry eye disease severity when investigating normal, moderate and severe cases of dry eye. Suzuki et $a l^{30}$ have stated: "Tear osmolarity correlates with dry eye severity and therefore could provide a biomarker for disease severity". Bechtel ${ }^{31}$, commenting on a poster prepared and presented at an American Academy of Ophthalmology meeting by Foulks, states that tear osmolarity may function as an accurate diagnostic tool in early dry eye disease. Investigating the variability of osmolarity, over a three month period, in dry eye disease, Sullivan et $a l^{32}$ indicate that osmolarity of the tear film had the lowest variability when compared with other commonly used tests for dry eye disease. Tomlinson et $a l^{33}$ determined a referent of 316 $\mathrm{mOsmol} / \mathrm{l}$ as a cut-off point for the diagnosis of dry eye. They also stated that "hyperosmolarity (defined as $>316 \mathrm{mOsmol} / \mathrm{l}$ ) was superior in overall accuracy to any other single test for dry eye diagnosis..." Gillan $^{34}$ has shown that the TearLab ${ }^{\mathrm{TM}}$ system provides reasonably accurate, repeatable and reproducible results when measuring osmolarity of a calibration/ test solution. Investigating the repeatability and accuracy of two different instruments, Yildiz et $a l^{35}$ were able to show that osmolarity measurements were repeatable when measuring four different solutions of different osmolarity. The methodology subcommittee of the Dry Eye Workshop ${ }^{7}$ has stated that: "Tear hyperosmolarity may reasonably be regarded as the signature feature that characterizes the condition of ocular surface dryness" and that the "...recommended cut-off value of $316 \mathrm{mOsmol} / \mathrm{l}$ can be said to be well validated".

If the use of questionnaires does enable one to diagnose dry eye and if osmolarity is the single best metric for determining the presence of dry eye, then it might not be unreasonable to expect some kind of relationship between the two diagnostic methods. The purpose of this study was to investigate whether any relationship exists between the symptoms of dry eye (as determined using the OSDI) and tear osmolarity measured using the TearLab ${ }^{\mathrm{TM}}$ osmolarity system.

\section{Method}

Forty optometry students (10 of whom were wearing contact lenses) studying at the University of Johannesburg volunteered to participate in this study. All students were aged between 19 and 25 years and gave written informed consent for the investigation. The tenets of the Declaration of Helsinki were adhered to throughout the study. Male and female subjects were included. The TearLab ${ }^{\mathrm{TM}}$ osmolarity system was used to measure the tear osmolarity of each subject (for a detailed exposition of how the TearLab ${ }^{\mathrm{TM}}$ system works and is used, the reader is referred to the TearLab ${ }^{\mathrm{TM}}$ system user manual). Prior to use the measuring pen was calibrated/checked by attaching the electronic check card to the measuring pen and then placed on the reader. The read-out for the electronic check card was within manufacturer specifications. Only the left eye of each subject was measured. Prior to measuring osmolarity a new test card was attached to the reader for each subject. The subject was seated comfortably and asked to "look up and to the right" after which the tip of the test card was gently placed onto the tear meniscus of the lower lid. No attempt was made to pull the lower lid from the eye. An effort was made to not irritate the eye when collecting the tear sample. Once the pen emitted a loud beep (indicating that an adequate sample had been collected) the pen was then docked onto the reading device within 40 seconds (according to manufacturer instructions). A measurement of tear osmolarity was produced by the reading device, which was then recorded. The test card was then removed from the pen and discarded.

Each subject completed the OSDI questionnaire within 24 hours of having tear osmolarity measured. The OSDI score is assessed on a scale of 0 to 100 with higher scores indicting greater disability related to dry eye. The developers of the OSDI provide an OSDI formula which is used to convert the answers on the OSDI questionnaire to an OSDI score ${ }^{20}$. This OSDI score is then used to determine the level of disability related to dry eye. The OSDI formula is:

\section{OSDI score $=\frac{(\text { sum of scores }) \times 25}{(\text { number of questions answered })}$}

(Readers interested in acquiring the OSDI and instructions for its use are referred to: dryeyezone. 
com where one can search for OSDI or search for OSDI using Google). An OSDI score was calculated for each subject. Statistical analysis was done using Medcalc statistical software for biomedical research.

\section{Results}

Table 1 shows the raw data collected in this study. Included in the table are the tear osmolarity for each subject, the OSDI score and whether the subject was wearing contact lenses or not. The mean osmolarity for the 40 subjects was $315.5 \pm 14.4 \mathrm{mOsmol} / 1$ (median: $314.0 \mathrm{mOsmol} / \mathrm{l}$ ) while the mean OSDI score was $23.5 \pm 16.6$ (median: $16.7 \mathrm{mOsmol} / \mathrm{l}$ ). Figure 1 shows box and whisker plots for the data collected where the box indicates values from the lower to the upper quartile, the middle line represents the median, the vertical line extends from the lowest to the highest value but excludes values that are considered to be outsider values (Figure 1a shows three data points not included on the vertical line).
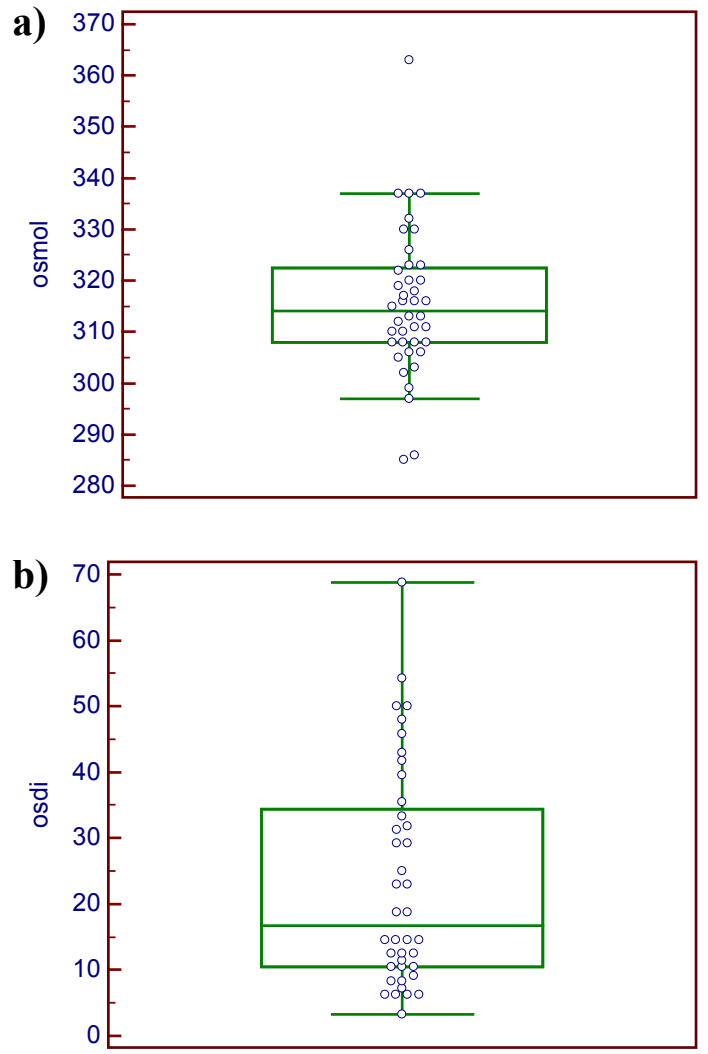

Figure 1. Box and whisker plots of medians and interquartile ranges are shown for tear osmolarity (Figure 1a) and OSDI score (Figure 1b). Circles indicate each measurement/score. See text for an explanation of the plots.
Table 1. Data collected from 40 subjects. Mean osmolarity is $315.5 \pm 14.4 \mathrm{mOsmol} / \mathrm{l}$ with the median $314.0 \mathrm{mOsmol} / \mathrm{l}$.

\begin{tabular}{|c|c|c|c|}
\hline Subject & $\begin{array}{l}\text { Osmolarity } \\
(\mathrm{mOsmol} / \mathrm{l})\end{array}$ & $\begin{array}{l}\text { OSDI } \\
\text { score }\end{array}$ & $\begin{array}{c}\text { Contact lens } \\
\text { wearer? }\end{array}$ \\
\hline 1 & 312 & 33.3 & $\mathrm{~N}$ \\
\hline 2 & 311 & 10.4 & $\mathrm{~N}$ \\
\hline 3 & 308 & 11.4 & $\mathrm{~N}$ \\
\hline 4 & 310 & 7.3 & $\mathrm{~N}$ \\
\hline 5 & 317 & 68.7 & $\mathrm{~N}$ \\
\hline 6 & 302 & 12.5 & $\mathrm{~N}$ \\
\hline 7 & 337 & 45.8 & $\mathrm{~N}$ \\
\hline 8 & 326 & 8.3 & $\mathrm{Y}$ \\
\hline 9 & 332 & 8.3 & $\mathrm{~N}$ \\
\hline 10 & 320 & 10.5 & $\mathrm{Y}$ \\
\hline 11 & 306 & 31.8 & $\mathrm{~N}$ \\
\hline 12 & 303 & 23.0 & $\mathrm{~N}$ \\
\hline 13 & 337 & 47.9 & $\mathrm{Y}$ \\
\hline 14 & 297 & 14.6 & $\mathrm{~N}$ \\
\hline 15 & 316 & 39.6 & $\mathrm{~N}$ \\
\hline 16 & 330 & 50.0 & $\mathrm{~N}$ \\
\hline 17 & 316 & 29.2 & $\mathrm{~N}$ \\
\hline 18 & 313 & 54.2 & $\mathrm{~N}$ \\
\hline 19 & 316 & 22.9 & $\mathrm{~N}$ \\
\hline 20 & 310 & 6.3 & $\mathrm{~N}$ \\
\hline 21 & 308 & 18.7 & $\mathrm{~N}$ \\
\hline 22 & 315 & 6.3 & $\mathrm{~N}$ \\
\hline 23 & 319 & 3.3 & $\mathrm{~N}$ \\
\hline 24 & 305 & 35.4 & $\mathrm{~N}$ \\
\hline 25 & 323 & 25.0 & $\mathrm{~N}$ \\
\hline 26 & 313 & 12.5 & $\mathrm{~N}$ \\
\hline 27 & 320 & 14.6 & $\mathrm{~N}$ \\
\hline 28 & 318 & 42.9 & $\mathrm{~N}$ \\
\hline 29 & 323 & 10.4 & $\mathrm{~N}$ \\
\hline 30 & 330 & 31.3 & $\mathrm{Y}$ \\
\hline 31 & 363 & 9.1 & $\mathrm{~N}$ \\
\hline 32 & 308 & 18.8 & $\mathrm{Y}$ \\
\hline 33 & 311 & 6.3 & $\mathrm{~N}$ \\
\hline 34 & 285 & 6.3 & $\mathrm{~N}$ \\
\hline 35 & 322 & 29.2 & $\mathrm{Y}$ \\
\hline 36 & 337 & 50.0 & $\mathrm{Y}$ \\
\hline 37 & 308 & 12.5 & $\mathrm{~N}$ \\
\hline 38 & 286 & 14.6 & $\mathrm{Y}$ \\
\hline 39 & 306 & 14.6 & $\mathrm{Y}$ \\
\hline 40 & 299 & 41.7 & $\mathrm{Y}$ \\
\hline
\end{tabular}


Figure 2 is a scatter plot of tear osmolarity versus OSDI score. Included is the linear regression line (solid blue line) as well as the $95 \%$ confidence interval for the regression line (dotted red line). There is no obvious trend to be seen in the data plotted. The regression equation is: $y=310.96+0.191 x$. A KolmogorovSmirnov test for normal distribution was conducted on each set of data and both sets of data were found to be normally distributed. A correlation coefficient was determined for the tear osmolarity and OSDI score data. A weak, positive, statistically insignificant, correlation between tear osmolarity and OSDI score was found $(r=0.22, p=0.17)$.

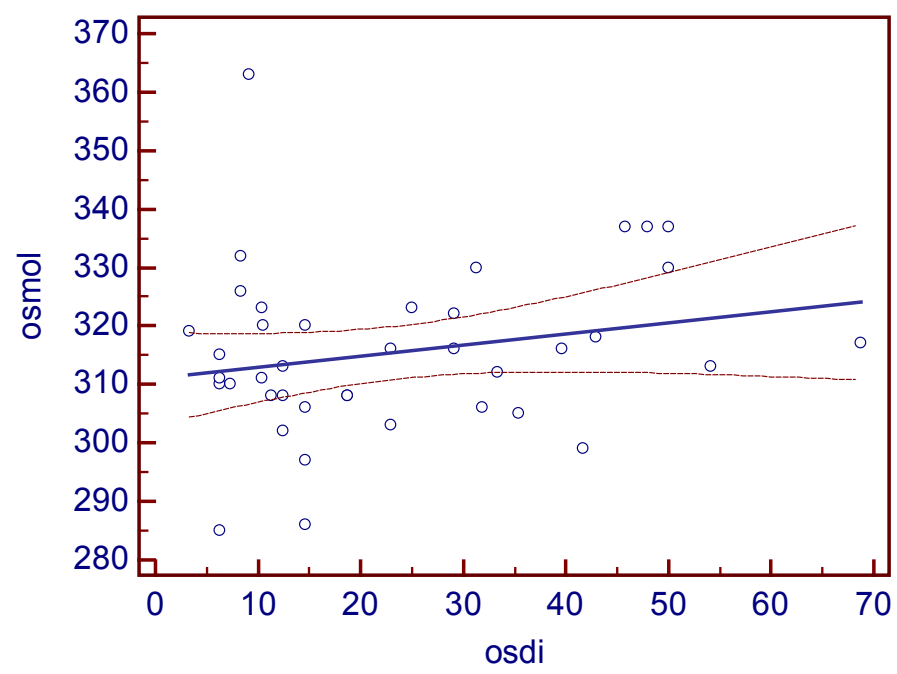

Figure 2. A scatter plot of tear osmolarity (osmol) versus OSDI score (osdi) is shown. Included is the linear regression line (solid blue line) with its associated $95 \%$ confidence interval (dotted red line), $(r=0.22 p=0.17)$.

A primary reason for contact lens intolerance is ocular dryness ${ }^{36}$ with reports that approximately $50 \%$ of contact lens wearers experience dry eye symptoms at least on some occasions ${ }^{37-39}$. Young et al have shown evidence suggesting that approximately $25 \%$ of symptomatic contact lens wearers do not have visible signs of ocular surface disease. The mean tear osmolarity for the 10 contact lens wearers in this sample of subjects was $317.1 \pm 16.9 \mathrm{mOsmol} / \mathrm{l}$. The mean OSDI score for the 10 contact lens wearers was $26.6 \pm 15.6$. A correlation coefficient between tear osmolarity and OSDI score was also determined for the 10 contact lens wearers of this sample. A weak (slightly stronger correlation than that seen when all 40 subjects were included) positive, statistically insignificant correlation between tear osmolarity and OSDI score was determined $(r=0.45, p=0.20)$. Figure 3 shows a scatter plot of the tear osmolarity versus OSDI for the ten contact lens wearers.

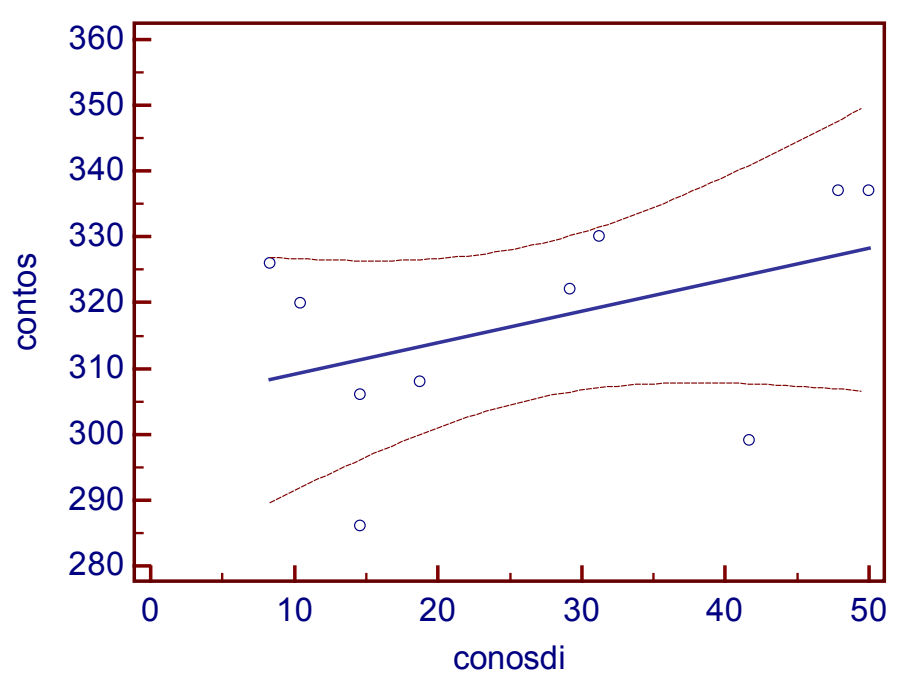

Figure 3. Tear osmolarity (contos) versus OSDI score (conosdi) data (for the ten contact lens wearers in this sample) is represented in this scatter plot. Included is the linear regression line (solid blue line) with its associated $95 \%$ confidence interval (dotted red line), $(r=0.45 p=0.20)$.

\section{Discussion}

The aim of this study was to determine if a relationship exists between the symptoms of dry eye (determined using the OSDI) and tear osmolarity (using the TearLab ${ }^{\mathrm{TM}}$ osmolarity system). Using questionnaires to diagnose dry eye is an important tool for clinicians ${ }^{7}$ with the suggestion having been made that questionnaires are more valuable in the diagnosis of dry eye than other tests ${ }^{13}$. Osmolarity has been touted as being the best single metric to use when attempting to diagnose dry eye $\mathrm{e}^{8,27-28}$ with Suzuki et $a l^{30}$ stating that "tear osmolarity correlates with dry eye disease...". Tomlinson et $a l^{33}$ have determined that a cut-off point of $316 \mathrm{~m}$ Osmol/1 should be used when using tear osmolarity for the diagnosis of dry eye.

The correlation between tear osmolarity and OSDI score in this sample of 40 optometry students has been shown to be weak and statistically insignificant. The same conclusion has been shown for the 10 subjects who wore contact lenses. These findings are in agreement with those shown by Dalton ${ }^{41}$ who, using 
the OSDI, the Single Item Dry Eye Questionnaire (SIDEQ) and the McMonnies Dry Eye Questionnaire (MMDEQ), found no correlation between the symptoms suggested by the questionnaires and tear osmolarity $(r=0.14, r=0.03$ and $r=0.27$ for the SIDEQ, OSDI and MMDEQ respectively). Nineteen $(47.5 \%)$ of the 40 subjects in this study had a tear osmolarity of $316 \mathrm{mOsmol} / 1$ or greater and using Tomlinson et $a l^{33}$ referent as a guideline, these 19 subjects could be classified as having dry eyes. However, when evaluating the correlation between tear osmolarity and OSDI score for the 19 subjects in this instance, a poor, negative, statistically insignificant correlation was found $(r=-0.06, p=$ 0.82 ). Using an OSDI score of 15 as a cut-off point for symptomatic individuals ${ }^{21,42-43}, 20$ of the $40(50 \%)$ subjects could be considered symptomatic for dry eye. Nevertheless, no relationship between tear osmolarity and OSDI score was found.

In conclusion, little correlation was found between tear osmolarity and OSDI score in the subjects investigated in this study. It is possible that the OSDI is a poor questionnaire for the diagnosis of dry eye (as suggested by Dougherty et $a l^{23}$, the OSDI does not ideally target dry eye disease) yet, as shown by Dalton ${ }^{41}$, other dry eye questionnaire results do not correlate with tear osmolarity either. Is the TearLab ${ }^{\mathrm{TM}}$ osmolarity system an accurate, repeatable and reproducible instrument to determine tear osmolarity? Several authors suggest that this is the case $\mathrm{e}^{28-29,34}$. The question as to how clinicians correctly decide if a patient has dry eye or not still seems to be a difficult one to answer.

\section{Acknowledgements}

My thanks to the following students for the collection of the data used in this study: C Meyer, $\mathrm{T}$ Miller, T Dangor and W McPherson.

\section{References}

1. Lemp MA (chair). The definition and classification of dry eye disease: report of the definition and classification subcommittee of the International Dry Eye Workshop. Oc Surf 20075 75-92.

2. McCarty CA, Bansal AK, Livingstone PM. The epidemiology of dry eye in Melbourne, Australia. Ophthalmol 1998105 1114-1119.

3. Lin PY, Tsai SY, Cheng CY. Prevalence of dry eye among an elderly Chinese population in Taiwan: the Shihpai study. Ophthalmol 2003110 1096-1101.

4. Moss SE, Klein R, Klein BEK. Prevalence of and risk factors for dry eye syndrome. Arch Ophthal 2000118 12641268.

5. Nicholls JJ, Mitchell L, Nicholls KK. An assessment of self-reported disease classification in epidemiological studies of dry eye. Inv Ophthal Vis Sci 200445 3453-3457.

6. Bandeen-Roche K, Muñoz B, Teisch JM, West SK, Schein OD. Self-reported assessment of dry eye in a population based setting. Inv Ophthal Vis Sci 199738 2469-2475.

7. Bron AJ (chair). Methodologies to diagnose and monitor dry eye disease. Report of the diagnostic methodology subcommittee of the International Dry Eye Workshop. Oc Surf 20075 108-152.

8. Khanal S, Tomlinson A, McFadyen A, Diaper C, Ramaesh K. Dry eye diagnosis. Inv Ophthal Vis Sci 200849 14071414.

9. Hay EM, Thomas E, Pal B, Hajeer A, Chambers H, Silman AJ. Weak association between subjective symptoms and objective testing for dry eyes and dry mouth: results from a population based study. Ann Rheum Dis 199857 20-24.

10. Schein OD, Muñoz B, Yielsch JM, Bandeen-Roche K, West S. Prevalence of dry eye among the elderly. Am J Ophthalmol 1997124 723-728.

11. Tomlinson A, Pearce EL, Simmons PA, Blades K. The effect of oral contraceptives on tear physiology. Ophthal Physiol Opt 200121 9-16.

12. Smith JA (chair). The epidemiology of dry eye disease: report of the epidemiology subcommittee of the International Dry Eye Workshop. Oc Surf 2007 5 93-107.

13. Guillon M, Maissa C. Dry eye symptomatology of soft contact lens wearers and non-wearers. Optom Vis Sci 2005 82 829-834.

14. Begley CC, Chalmers RL, Abetz L, Venkataraman K, Mertzanis P, Caffery BA, Snyder C, Edrington T, Nelson D, Simpson T. The relationship between habitual patientreported symptoms and clinical signs among patients with dry eye of varying severity. Inv Ophthal Vis Sci 200344 4753-4761.

15. Lemp MA. Advances in understanding and managing dry eye disease. Am J Ophthalmol 2008146 350-356.

16. Simmons LB, Vehige JG, Carlisle C, Felix C. Comparison of dry eye signs in self-described mild and moderate patients. Inv Ophthal Vis Sci 200344 e-abstract 2448.

17. Narayanan S, Miller R, Prager TC, Jackson JA, Leach NE, McDermott AM, Christensen MT, Bergmanson JPC. The diagnosis and characteristics of moderate dry eye in noncontact lens wearers. Eye Contact Lens 200531 96-104.

18. Gulati A, Sullivan R, Buring JE, Sullivan DH, Dana R, Schaumberg DA. Validation and repeatability of a short questionnaire for dry eye syndrome. Am J Ophthalmol 2006142 125-131.

19. Johnson ME, Murphy PJ. Measurement of ocular surface irritation on a linear interval scale with the ocular comfort index. Inv Ophthal Vis Sci 200748 4451-4458.

20. Walt JG, Rowe MM, Stern KL. Evaluating the functional impact of dry eye: the Ocular Surface Disease Index 
(abstract). Drug Inf J 1997311436.

21. Schiffman RM, Christianson MD, Jacobsen G, Hirsch JD, Reis BL. Reliability and validity of the Ocular Surface Disease Index. Arch Ophthalmol 2000118 615-621.

22. Ozcura F, Aydin J, Helvaci MR. Ocular Surface Disease Index for the diagnosis of dry eye syndrome. Oc Immunol Inflamm 200715 389-393.

23. Dougherty BE, Nichols JJ, Nichols KK. Raasch analysis of the Ocular Surface Disease Index (OSDI). Inv Ophthal Vis Sci 201152 8630-8635.

24. Friel JP (dictionary editor). Dorland's illustrated medical dictionary $26^{\text {th }}$ ed. Philadelphia: Igaku-Shoin/Saunders, 1981.

25. Gilbard JP, Farris RL, Santamaria J. Osmolarity of tear microvolumes in keratoconjunctivitis sicca. Arch Ophthalmol 197896 677-681.

26. Osmolarity system: user manual. Tearlab Corporation San Diego, USA.

27. Lemp MA, Bron AJ, Bardouin C, Benítez del Castillo JM, Geffen D, Tauber J, Foulks GN, Pepose JS, Sullivan DB. Tear osmolarity in the diagnosis and management of dry eye disease. Am J Ophthalmol 2011151 792-798.

28. Benelli U, Naradi M, Posarelli C, Albert TG. Tear osmolarity measurement using the TearLab osmolarity system in the assessment of dry eye treatment and effectiveness. Contact Lens Ant Eye 201033 61-67.

29. Sullivan BD, Whitmer D, Nichols KK, Tomlinson A, Foulks GN, Geerling G, Pepose JS, Kosheleff V, Porreco A, Lemp MA. An objective approach to dry eye disease severity. Inv Ophthal Vis Sci 201051 6125-6130.

30. Suzuki M, Massingale ML, Ye F, Godbold J, Elfassy T, Vallabhajosyula M, Asbell PA. Tear osmolarity as a biomarker for dry eye disease severity. Inv Ophthal Vis Sci 201051 4557-4561.

31. Bechtel B. Tear osmolarity may function as a biomarker of dry eye disease. Oc Surg News 2010 July.

32. Sullivan BD, Crews LA, Sönmez B, de la Paz MF, Comert E, Charoenrook V, de Araujo AL, Pepose JS, Berg MS, Kosheleff VP, Lemp MA. Clinical utility of objective tests for dry eye disease: variability over time and implications for clinical trials and disease management. Cornea 201231 1000-1008.

33. Tomlinson A, Khanal S, Ramaesh K, Diaper C, McFadyen A. Tear film osmolarity: determination of a referent for dry eye diagnosis. Inv Ophthal Vis Sci 200647 4309-4315.

34. Gillan WDH. Repeatability and reproducibility of TearLab measurements. S Afr Optom 201372 19-24.

35. Yildiz EH, Fan VC, Banday H, Ramanathan LV, Bitra RK, Garry F, Asbell PA. Evaluation of a new tear osmometer for repeatability and accuracy using $0.5-\mu \mathrm{l}$ (500 nanolitre) samples. Cornea 200928 677-686.

36. Pritchard N, Fonn D. Dehydration, lens movement and dryness ratings of hydrogel contact lenses. Ophthal Physiol Opt 199515 281-286.

37. Doughty MJ, Fonn D, Richter D, Simpson T, Caffery B, Gordon K. A patient questionnaire approach to estimating the prevalence of dry eye symptoms in patients presenting to optometric practices across Canada. Optom Vis Sci 1997 74 624-631.
38. Nichols JJ, Mitchell GL, Nichols KK, Chalmers R, Begley CG. The performance of the contact lens dry eye questionnaire as a screening survey for contact lens-related dry eye. Cornea 200221 469-475.

39. Begley CG, Caffery B, Nichols KK, Chalmers R. Responses of contact lens wearers to a dry eye survey. Optom Vis Sci 200077 40-46.

40. Young G, Chalmers R, Napier L, Kern J, Hunt C, Dumbleton K. Soft contact lens-related dryness with and without clinical signs. Optom Vis Sci 201289 1125-1132.

41. Dalton KN. The investigation of tear film osmolality as a clinical instrument used in assessments of the tear film and dry eye disease. Master's degree thesis, University of Waterloo, Canada, 2009.

42. Pult H, Riede-Pult BH. Non-contact meibography: keep it simple but effective. Contact Lens Ant Eye 201235 77-80.

43. Pult H, Purslow C, Murphy PJ. The relationship between clinical signs and dry eye symptoms. Eye (Lond) 201125 502-510. 